\title{
ELECTRONS AT LOW ALTITUDES: \\ A DIFFICULT BACKGROUND PROBLEM \\ FOR SOFT XRAY ASTRONOMY
}

F. D. Seward

R. J. Grader

\&.Toor

G. A. Burginyon

R. W. Hill

October 24, 1973

Prepared for US. Atomic Energy Commission under contract No.W-7405-Eng-48 


\title{
NOTYE
}

\begin{abstract}
This report was prepated as sn aceount of wosk spontored by the United States Goremment. Neither the United States no the United States Atomic Eneray Commission, nor any of their employees, nor any of their contractors, subantreciors, or their employech, mikes any wirnaty, express of implied, of or thet eny lepl tiability of thpondibitity for the aceuracy, of assume or wefuiness of any ipforites ditelosed, or represests that its use would pot in fin or pracess

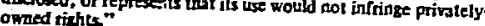

\section{Printed in the United States of America Available from \\ National Technical Information Service \\ U.S. Department of Commerce 5285 Port Royal Road Springfield, Virginia 22151}

Price: Printed Copy $\$$ $\approx$; Microfiche $\$ 0.95$

\begin{tabular}{c} 
yages \\
\hline $1-50$ \\
$51-150$ \\
$151-325$ \\
$326-500$ \\
$501-1000$
\end{tabular}

NTIS Selling Price $\$ 4.00$

$\$ 5.45$

$\$ 7.60$

$\$ 10.60$

$\$ 13.60$ 
TID -4500, UC $-34 b$

Physics -Cosmic and Terrestrial

\section{㢟}

\section{LAWRENCE LNERMORE LABORATORY}

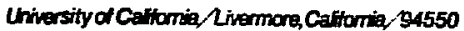

UCRL-51470

\section{ELECTRONS AT LOW ALTITUDES:}

A DIFFICULT BACKGROUND PROBLEM FOR SOFT $X$-RAY ASTRONOMY

\section{F. D. Seward}

R. J. Grader

A. Toor

G. A. Burginyon

R. W. Hill

MS. date: October 24, 1973

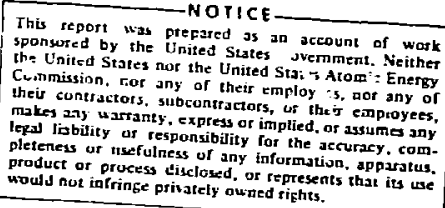

This report was prepused

sponswed by the United Stiles

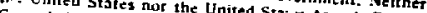

theis coner. ror any of their employ -5, not any of

pleteness us as responsibijity for the accuracy, com

would not infrecess tisclosed. or represents that ins use 


\section{Contents}

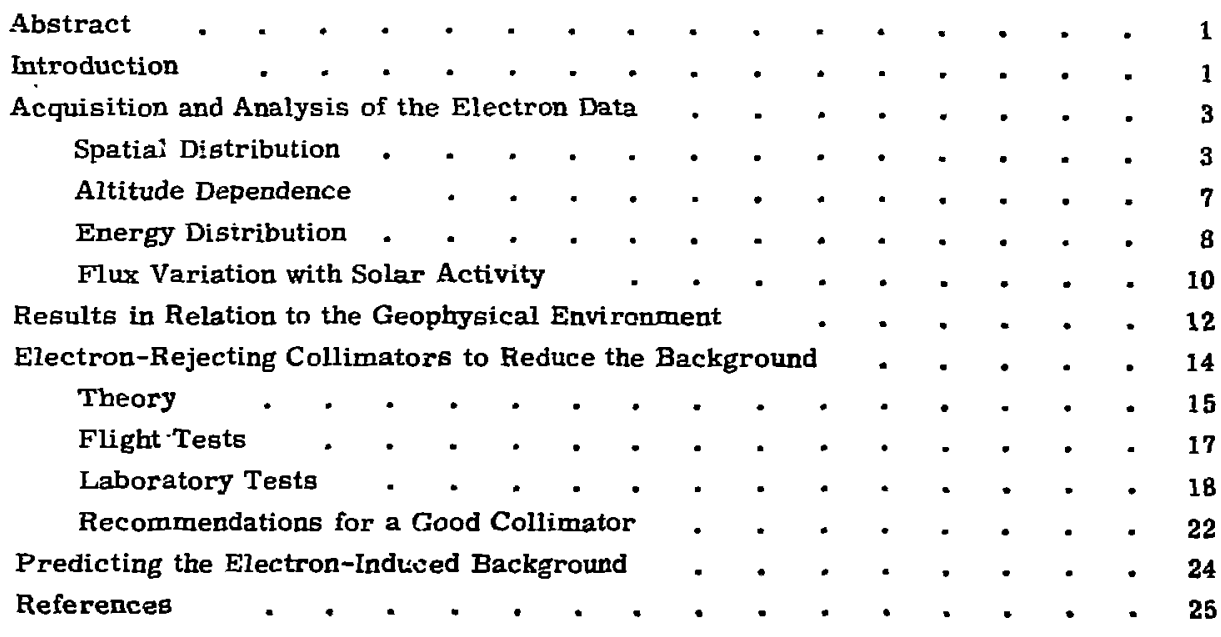




\title{
ELECTRONS AT LOW ALTITUDES: A DIFFICULT BACKGROUND PROBLEM FOR SOFT X-RAY ASTRONOMY
}

\author{
Abstract \\ Quasi-trapped and precipitating \\ electrons have been observed with \\ rocket-borne $\mathrm{x}$-ray astronomy detectors \\ in the altitude range 150 to $500 \mathrm{~km}$. \\ Becanse the flights occurred at low \\ magnetic latitudes the electrons were \\ unexpected. Data from many flights \\ are combined to derive alitude depend- \\ ence, an average electron spectrum, \\ and variation with solar activity. De- \\ velopment of electron-rejecting colli- \\ mators is discussed, and laboratory \\ and flight data on these collimators \\ are presented.
}

\section{Introduction}

Our x-ray astronomy observations made with rocket-borne instruments have repeatedly shown a strong background due to electrons. The existence of these electrons surprised us, since the rocket flights were at low latitudes and at altitudes supposedly well below the radiation belts. No electron detectors were carried on the rockets, but we have been able to derive a considerable amount of data on the electrons from the $x$-ray detector observations. In this report we summarize 14 observations of such electrons and describe our continuing efforts to make an efficient $x$-ray collimator that rejects electrons completely, which has turned out to be a difficult problem.

The salient facts about these electrons are as follows:

- Counters with very thin windows ( $<0 \mu \mathrm{g} / \mathrm{cm}^{2}$ ) are needed to observe the electrons clearly - the thinner the win- dow, the larger the electron-induced counting rate. Such counters are a fairly recent development.

- The flux of electrons shows a definite dependence on direction.

- The flux is dependent or. solar activity.

The detectors we use for $x$-ray observations have thin windows and large area, making them highly sensitive to the low fluxes of low-energy electrons encountered on the rocket fiights. Slat-ty-e collimators with smooth metal vanes prodice a narrow $x$-ray field of view for the counters. These collimators easily scatter into the counters any electrons that arrive at nearly normal incidence, since small-angle electron scattering is very efficient. The collimators do exclude electrons arriving at large angles to the normal, and therefore it is possible to measure from the counter data the 
direction of electron flux. Analysis of the electron spectrum is di ficult, however, because a large but unknown proportion of the electron events in the counter represents electrons that bave been scattered from the collimator.

Figure 1 shows some unpublisled data, from a rocket-borne detector with a very thin window, to illustrate tine electron problem. Two prominent $x$-ray sources can be seen between regions of strong electron-induced background whose level is 2.5 times that of the normal background from cosmic rays and diffuse $x$ rays. This strong electron background is present in spite of a collimator designed to reject electrons by means of a magnetic field.

To obtain useful electron information from our $x$-ray astronomy data, we have combined date from flights at three geographica locations in the Pacific: Kauai (one of the Hiawaiian Islands), Johnston Island, and a site at $27^{\circ} \mathrm{N} 125^{\circ} \mathrm{W}$. The besic geophysical features are similar for these three locations, although magnetic field conditions are slightly different. We have derived a consistent set of

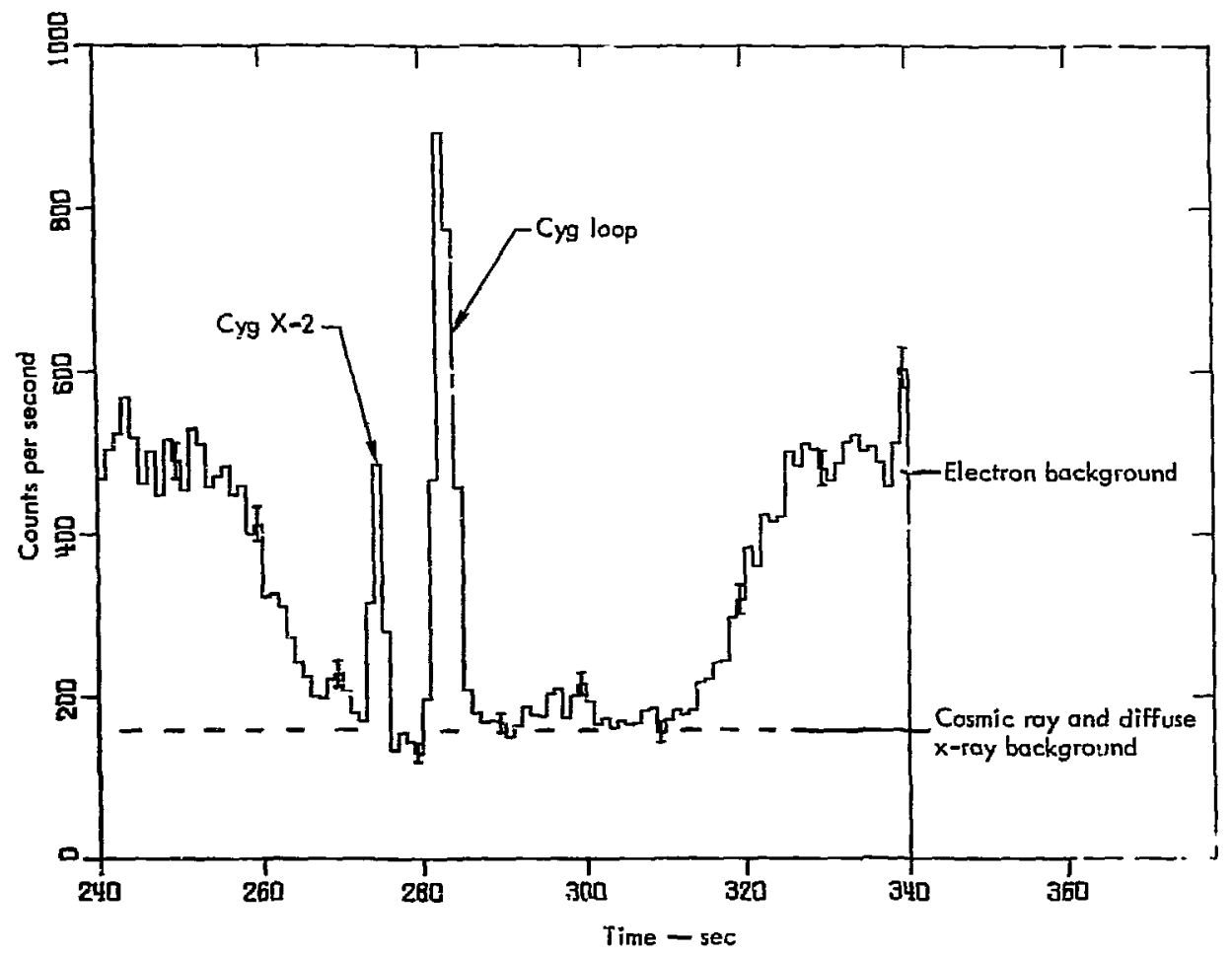

Fig. 1. X-ray detector data from a slow scan through the Cygnus region, made during a flight on May 20, 1972. Electron background is 2.5 times the normal background due to cosmic rays and diffuse $x$ rays. Counts shown are events depositing $0.2-4.0 \mathrm{keV}$ in the counter. 
electron data in this way, obtaining an electron spectrum -bove the atmosphere, the altitude dependence of the electron flux, and the variation of the electron flux with solar activity. These results are valid for the Kauai Range and probably also for other similar locations. The expected variation of electron flux with geographic location is discussed elsewhere. ${ }^{1}$

In this repori we first derive data on the obs = rved electrons and then discuss our efforts to shield the $\mathrm{x}$-ray detectors from tive electrons. Our goal for the past two years has been to make an efficient $\mathbf{x}$-ray collimator that rejects electrons completely. It has been quite diffi cult to eliminate electron events from the $x$-ray astronomy data. Our hopes have been falsely encouraged by misleading data from early flights and laboratory measurements. We have now reanalyzed all flight data and made new laborntory measurements of the efficiency with which various collimators reject electrons. This report summarizes our present understanding of the probler..

\section{Acquisition and Analysis of the Electron Data}

Table 1 summarizes the basic information about our rocket flights on which electrons have been observed. The detectors were in a'1 cases proportional counters. To be , etected, an electron had to pass through the counter window and deposit sufficient energy in the counter gas to create a pulse larger than the discriminator setting. Two discriminators were used: an upper level discriminator (ULD) and a lower level discriminator (LLD).

Counting rate data from these flights is shewn in Figs. 1-5 and also in Figs, 14 and 15 (later in the report).

\section{SPATIAL DISTRIBUTION}

Many of the flights had an attitude control system (ACS). On such flights, maneuvers were set up to scan particular astronomical rejions of interest. These maneuvers were not planned for electron measurements, and thus the electron data are usually incomplete as regards distri- bution relative to the magnetic field lines. Nevertheless, some nights have produced a fairly complete magnetic scan, and electron angular distributions around the magnetic field lines have been derived.

We find it helpful to think in terms of two separate electron distributions: (1) "Perpendicular" electrons, which move perpendicular to the field lines and consequently mirror in the vicinity of the rocket. 'These are at best "quasitrapped" since they cunnot drift completely around the earth on the L-shell in which they move. (2) "Parallel" electrons, whose distribution is very broad and is centered in a direction parallel to the field line. These parallel electrons come down the field line and directly into the atmosphere below the rocket. We have analyzed our data assuming on'y these two electron distributions are present.

A good example of perpendicular eiectrons is given in Fig. 2, which shows dnta from a sfinning rocket that carried two 
Table 1. Summary of information on rocket flights on which electrons have been observed.

\begin{tabular}{|c|c|c|c|c|c|c|c|c|c|c|c|c|}
\hline \multirow[b]{3}{*}{ Date } & \multirow[b]{3}{*}{$\begin{array}{c}\text { Launch } \\
\text { Bite }\end{array}$} & \multirow{3}{*}{$\begin{array}{l}\text { Rocket } \\
\text { orlen- } \\
\text { tatlona }\end{array}$} & \multirow[b]{3}{*}{$\begin{array}{c}\text { Apogee } \\
(\mathrm{km})\end{array}$} & \multicolumn{4}{|c|}{ Collimator } & \multirow{3}{*}{$\begin{array}{c}\text { Window } \\
\text { material } \\
\text { and } \\
\text { thickness } \\
\left(\mathrm{mg} / \mathrm{cm}^{2}\right)\end{array}$} & \multirow{2}{*}{\multicolumn{3}{|c|}{$\begin{array}{c}\text { Energy thresholds } \\
\text { (keV) }\end{array}$}} & \multirow{3}{*}{$\begin{array}{c}\text { 5-day } \\
\text { sum } \\
\text { of } A_{p} \\
\end{array}$} \\
\hline & & & & \multirow{2}{*}{$\begin{array}{l}\text { Field of } \\
\text { view } \\
\text { (FWHM) }\end{array}$} & \multirow[b]{2}{*}{ Material } & \multirow[b]{2}{*}{$\begin{array}{l}\text { Electron } \\
\text { rejection }\end{array}$} & \multirow{2}{*}{$\begin{array}{c}\text { scattering } \\
\text { cutorf } \\
\text { energy } \\
\text { (keV) }\end{array}$} & & & & & \\
\hline & & & & & & & & & LLD & ULD & $\begin{array}{l}\text { Back } \\
\text { counter }\end{array}$ & \\
\hline $5 / 15 / 68$ & Keuai & Spinning & 163 & $5^{\circ} \times 30^{\circ}$ & $\begin{array}{l}\text { Painted } \\
\text { brass }\end{array}$ & None & - & $\begin{array}{l}\text { Formvar } \\
(0.06)\end{array}$ & 3.5 & 11 & - & 79 \\
\hline $11 / 3 / 88$ & $\begin{array}{l}27 N \\
125 \mathrm{~W}\end{array}$ & Spinning & 225 & $2.5^{\circ} \times 30^{\circ}$ & $\begin{array}{l}\text { Painted } \\
\text { aluminum }\end{array}$ & None & - & $\begin{array}{l}\text { Mylar } \\
(0.53)\end{array}$ & - & 19 & - & 368 \\
\hline $11 / 7 / 68$ & $\begin{array}{l}\text { John- } \\
\text { gton Is. }\end{array}$ & $\mathrm{ACS}$ & 314 & $1.5^{\circ} \times 30^{\circ}$ & Aluminum & None & - & $\begin{array}{l}\text { Formvar } \\
(0.06)\end{array}$ & 3.5 & 5.5 & 一 & 157 \\
\hline $5 / 17 / 69$ & Kaugl & Spinning & 150 & $5^{\circ} \times 32^{\circ}$ & $\begin{array}{l}\text { Painted } \\
\text { brass }\end{array}$ & None & - & $\begin{array}{l}\text { Formvar } \\
(0.06)\end{array}$ & 3.5 & 11 & - & 271 \\
\hline $5 / 12 / 70$ & Kauai & ACS & 300 & $1.3^{\circ} \times 20^{\circ}$ & Copper & $\begin{array}{l}\text { Electro- } \\
\text { Btatic }\end{array}$ & 33 & $\begin{array}{l}\text { Formvar } \\
(0.07)\end{array}$ & 4.0 & 5.5 & 60 & 19 \\
\hline $9 / 24 / 70$ & $\begin{array}{l}\text { John- } \\
\text { ston Is. }\end{array}$ & ACS & 500 & $1.8^{\circ} \times 15.5^{\circ}$ & Aluminum & $\begin{array}{l}\text { Pulse shape } \\
\text { discrin)- } \\
\text { inator }\end{array}$ & - & $\begin{array}{l}\text { Mylar } \\
(3.5)\end{array}$ & - & 45 & - & 74 \\
\hline $5 / 26 / 71$ & Kaual & $\mathrm{ACS}$ & 300 & $1.3^{\circ} \times 20^{\circ}$ & Copper & $\begin{array}{l}\text { Electro- } \\
\text { static }\end{array}$ & 33 & $\begin{array}{l}\text { Formvar } \\
(0.07)\end{array}$ & 4.0 & 5.5 & 60 & 34 \\
\hline $10 / 23 / 71$ & Kauai & $A C S$ & 300 & $1.3^{\circ} \times 20^{\circ}$ & Copper & $\begin{array}{l}\text { Electro- } \\
\text { static }\end{array}$ & 50 & $\begin{array}{l}\text { Formvar } \\
(0.06)\end{array}$ & 3.5 & 5.5 & 60 & 22 \\
\hline $11 / 17 / 71$ & $\begin{array}{l}27 N \\
125 W\end{array}$ & Spinning & 267 & $3^{\circ} \times 20^{\circ}$ & Brass & Magnetlc & 78 & $\begin{array}{l}\text { Formvar } \\
(0.07)\end{array}$ & - & - & - & 9 \\
\hline $5 / 20 / 72$ & Kauai & ACS & 321 & $2^{\circ} \times 12^{0}$ & Aluminum & Magnetic & 53 & $\begin{array}{l}\text { Formvar } \\
(0.035)\end{array}$ & 2.5 & 5.5 & - & 70 \\
\hline $10 / 20 / 72$ & Kaual & ACS & 310 & $1.3^{\circ} \times 20^{\circ}$ & $\begin{array}{l}\text { Chemi- } \\
\text { cally } \\
\text { blackened } \\
\text { Cu }\end{array}$ & Magnetic & 200 & $\begin{array}{l}\text { Formvar } \\
(0.09)\end{array}$ & 5.0 & 6.0 & 60 & 67 \\
\hline $10 / 21 / 72$ & Kauai & ACS & 325 & $2^{\circ} \times 15^{\circ}$ & Copper & $\begin{array}{l}\text { Electro- } \\
\text { static }\end{array}$ & 11 & $\begin{array}{l}\text { Formvar } \\
(0.027)\end{array}$ & 2.0 & 3.5 & - & 73 \\
\hline $4 / 25 / 73$ & $\begin{array}{l}27 N \\
125 W\end{array}$ & Spinning & 280 & $6^{\circ} \times 7^{\circ}$ & $\begin{array}{l}\text { Painted } \\
\text { aluminum }\end{array}$ & $\begin{array}{l}\text { None and } \\
\text { magnetic }\end{array}$ & $\begin{array}{r}0 \\
41\end{array}$ & $\begin{array}{l}\text { Formvar } \\
(0.06)\end{array}$ & 3.5 & 5,0 & - & 139 \\
\hline $6 / 23 / 73$ & Kaual & $\mathrm{ACS}$ & 300 & $1.1^{\circ} \times 15^{\circ}$ & $\begin{array}{l}\text { EDN } \\
\text { aluminum }\end{array}$ & Magnetic & 600 & $\begin{array}{l}\text { Formvar } \\
(0.06)\end{array}$ & 3.5 & 5.0 & 60 & 75 \\
\hline
\end{tabular}

$a_{\text {ACS }}=$ attitude control system. 


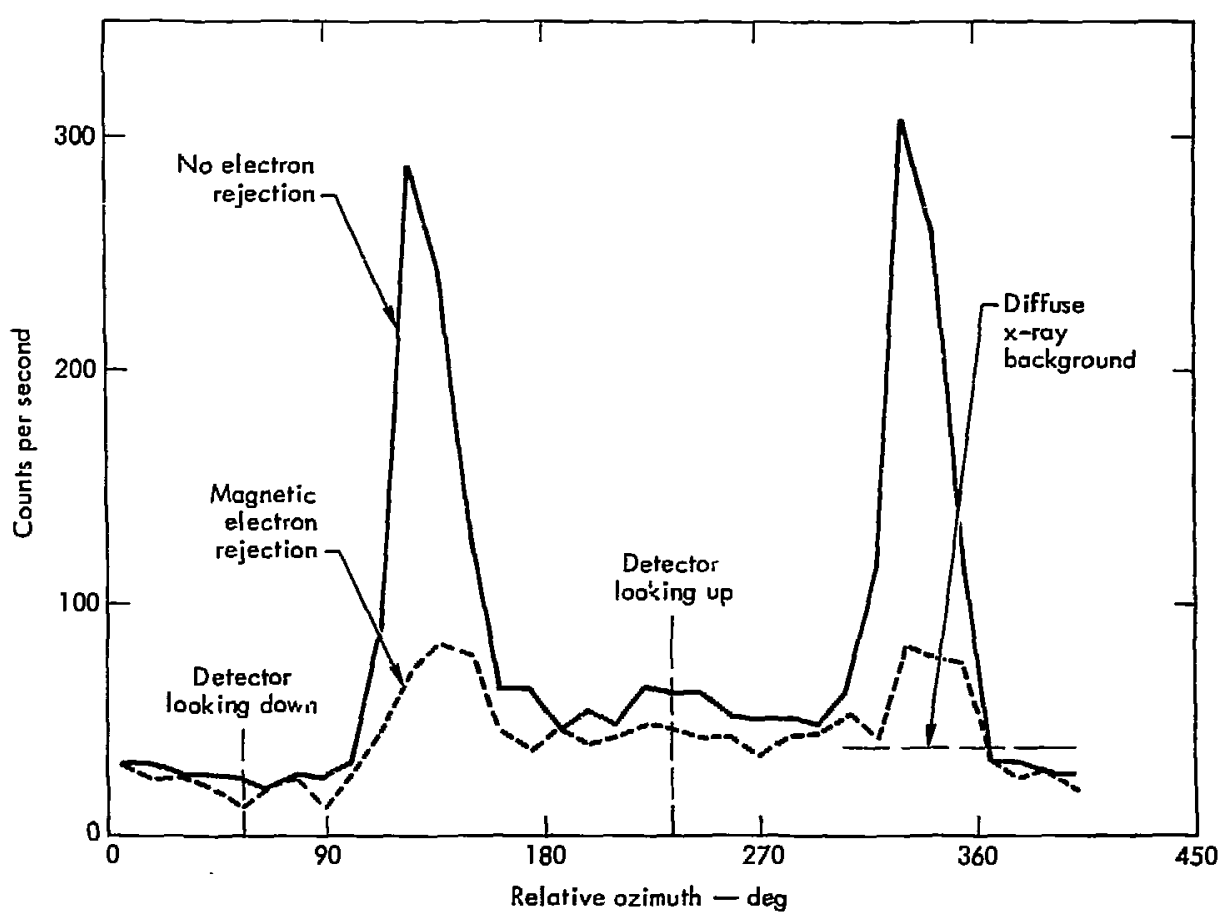

Fig. 2. Perpendicular electrons (i.e., electrons moving perpendicular to the magnetic Field lines) observed during a flight on April 25, 1973. Altitude was $280 \mathrm{~km}$. electron threshold $\sim 5 \mathrm{keV}$ (ULD).

identical counters. Both counters were collimated to give the same field of view $\left(6^{\circ} \times 7^{\circ} \mathrm{FWHM}\right)$, but one collimator had a magnetic field to reject electrons while the other collimator had no magnetic field. The difference between the two counting rates shows the electron flux. Maximum flux is seen twice per revolution when the detector points perpendiclilar to the earth's magnetic field lines. A smaller parallel electron flix appears almost isotropically when the detector is looking up from the atmosphere.

Figure 3 shows a pure parallel electron distribution observed from a spinning rocket at lower altitude. Two strong $x$-ray sources appear superposed on the electron-induced background.

Figures 4 and 5 show data from two attitude-controlled flights. They illustrate the appearance of electrons in iypical flight data and show how well these data may be fitted by assuming the two electron distributions. In both these figures the histogram is the counting rate above the upper level discriminator of a methane-filled counter. The entire flight, from launch to reentry, is shown. Solid and dashed curres are respectively the contributions of perpendicular and parallel electrons. The flux and spatia1 width of these two populations have been 


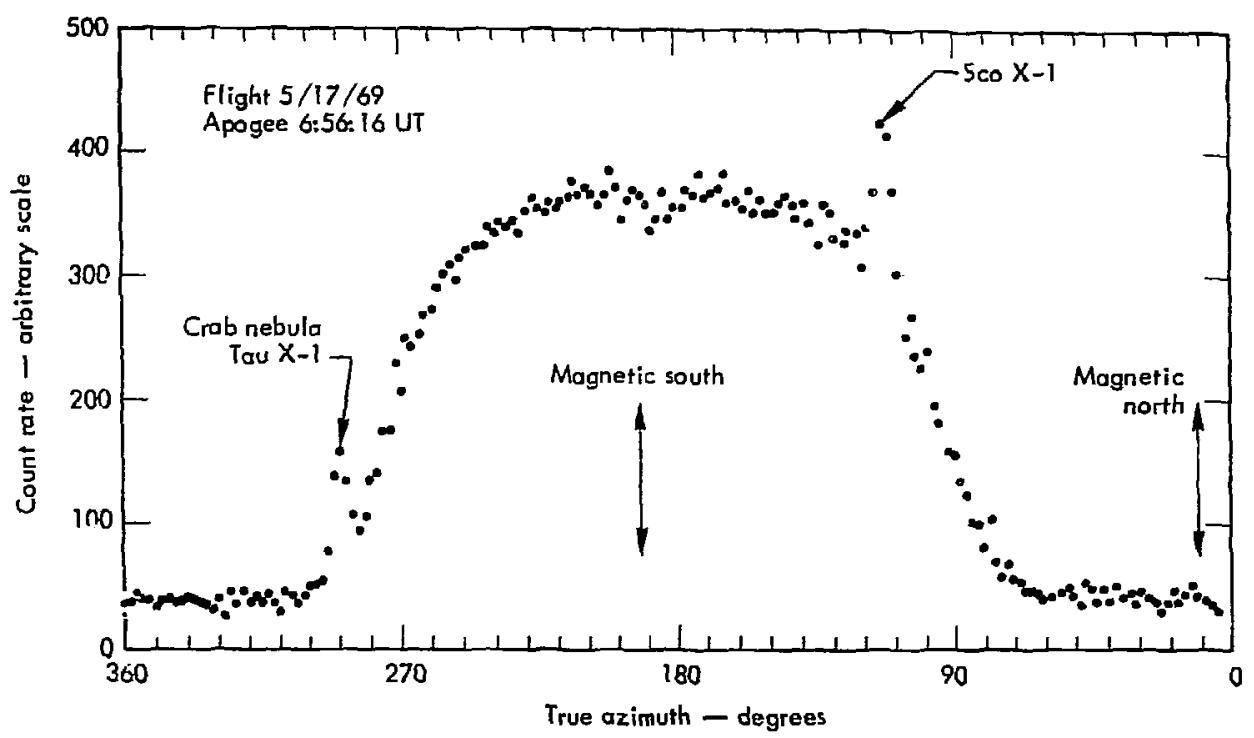

Fig. 3. Parallel electrons (i.e., electrons moving parallel to the magnetic field lines) observed during a flight on May 17, 1969. Altitude $\sim 150 \mathrm{~km}$, electron threshold $3.5 \mathrm{keV}$.

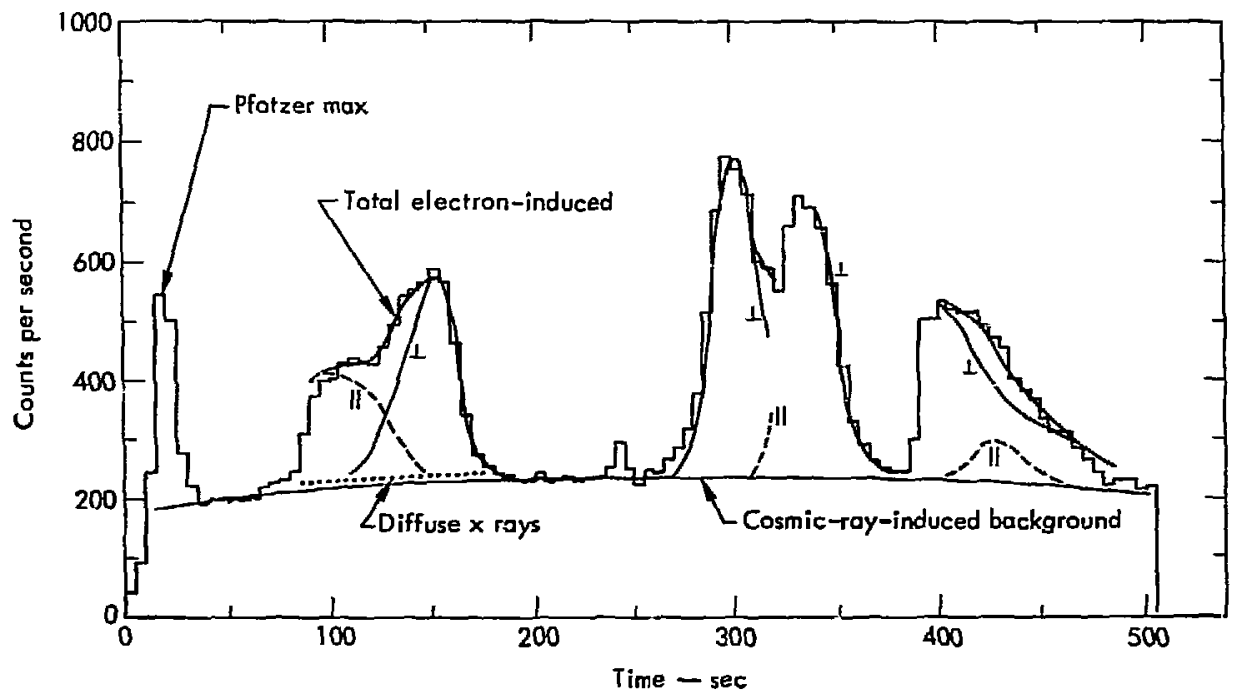

Fig. 4. Electrons observed during a flight on May 26, 1971. Counts above ULD $(5.5 \mathrm{keV})$ vs time. 


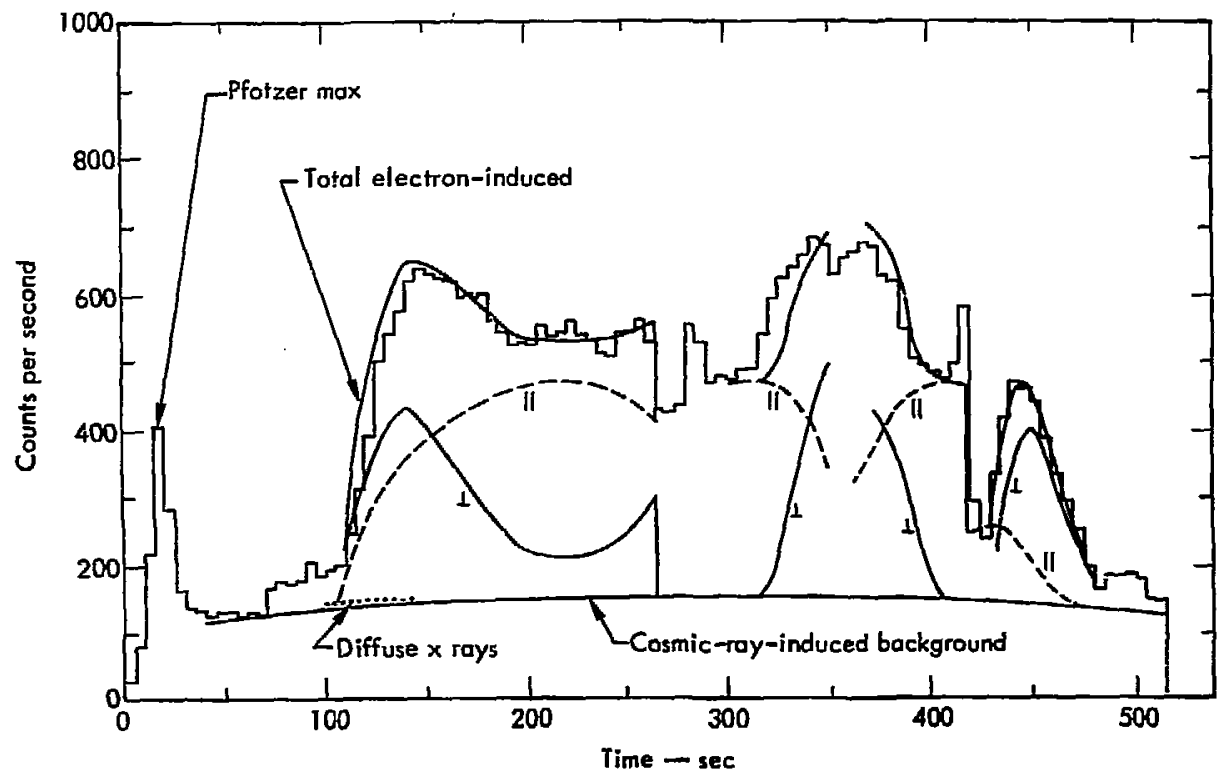

Fig. 5. Electrons observed during a flight on October 20, 1972. Counts above ULD $(6.0 \mathrm{keV})$ vs time.

adjusted to give a good fit to the data. The altitude dependence of each group has been derived from these data. Gaps in the calculated curves correspond to times when the payload was maneuvering to set up the next slow scan. During some of these maneuvers the motion is too rapid to determine the position well.

The most electron-free observations occur when the detector is looking down the magnetic field line toward the atmosphere. Electron flux in this hemisphere is a minimum and the part that is not occulted by the earth is suitable for $\mathrm{x}$-ray observations.

\section{ALTITUDE DEPENDENCE}

The altitude dependence of perpendicular electrons has been derived from spinning rockets which sampled the directional nux throughout the night and from a few suitable ACS nights. These data are shown in Fig. 6. The solid curves, normalized to each set of data points, vary inversely as the square root of the atmospheric density. The variation in flux from flight to flight is due to the different energy thresholds of the detectors and to changing solar activity. The dats from any one flight, however, are reasonably well fitted by the curves shown.

To calculate atmospheric density the appropriate CIRA atmosphere was used. ${ }^{2}$ Thus, fluctuations of atmospheric density with solar activity and time of day have been somewhat compensated for.

Figure 7 shows the measured fluxes of parallel electrons. This flux at any one 


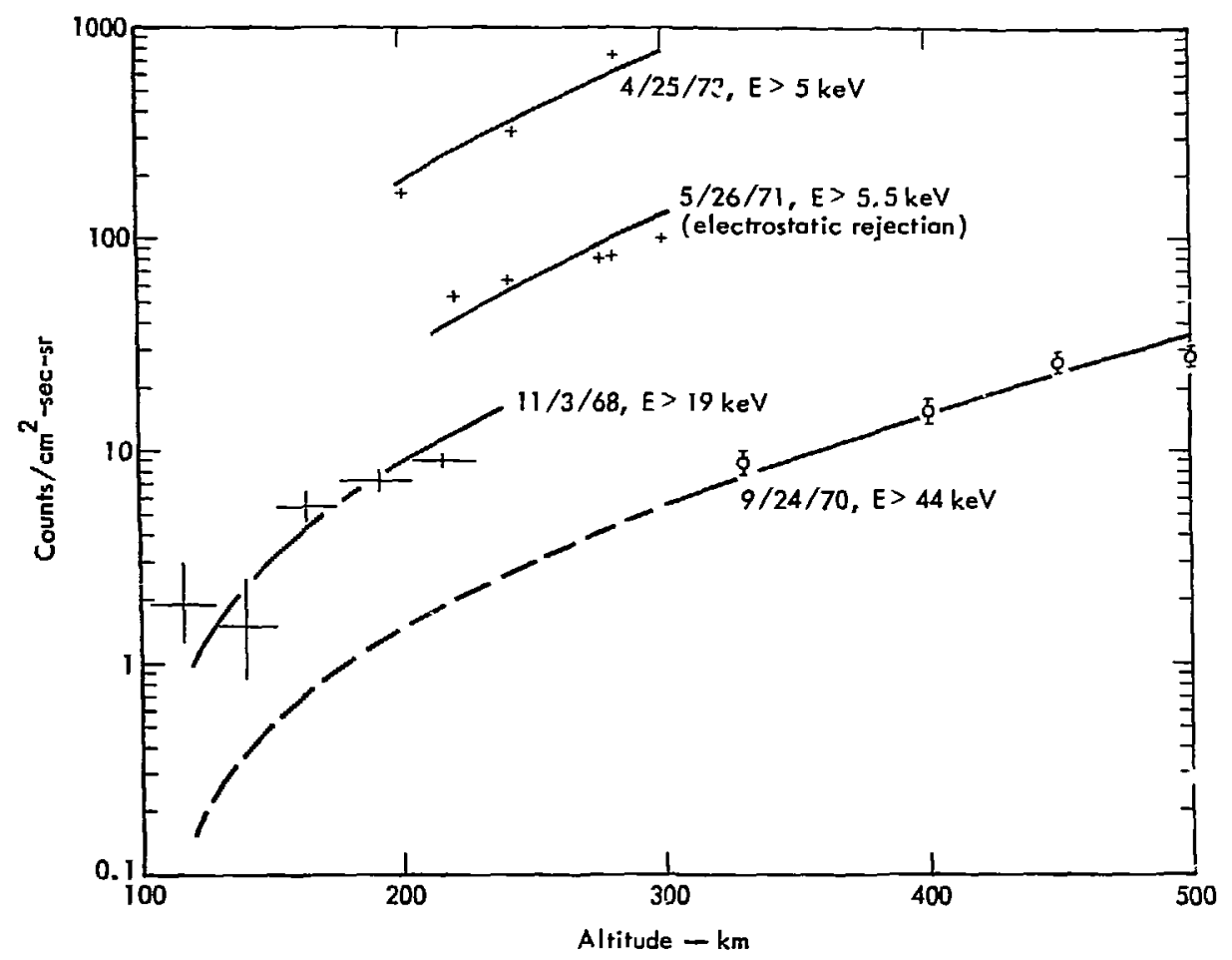

Fig. 6. Altitude dependence of perpendicular electrons as observed on four flights (ULD data).

time is fairly constant above $200 \mathrm{~km}$. There is a great variation from flight to flight which is mostly due to changing solar activity.

The energy threpholds determined by the window have been listed for those experiments carrying electrostatic collimators. These collimators were run at about $250 \mathrm{~V}$ potential; as we will show later, this had little effect on the measured electron flux.

LLD data have been used for two early flights since the ULD was set very high on these detectors. The solid lines in Fig. 7 are smooth curves drawn through the data points of a given flight.

\section{ENERGY DISTRIBUTION}

Most of our detector systems have two discriminators. The LLD is set at the minimum $x$-ray energy of interest, and the ULD at the maximum $x$-ray energy acceptable in the counter. Typical settings are 0.2 and $2.5 \mathrm{keV}$. Virtually all background events caused by high energy particles such as cosmic rays traversing the detector appear above the upper level discriminator. In the absence of electrons, the in-flight background observed above the ULD is quite constant, varying only slightly with altitude. This is the data channel where electrons are seen 


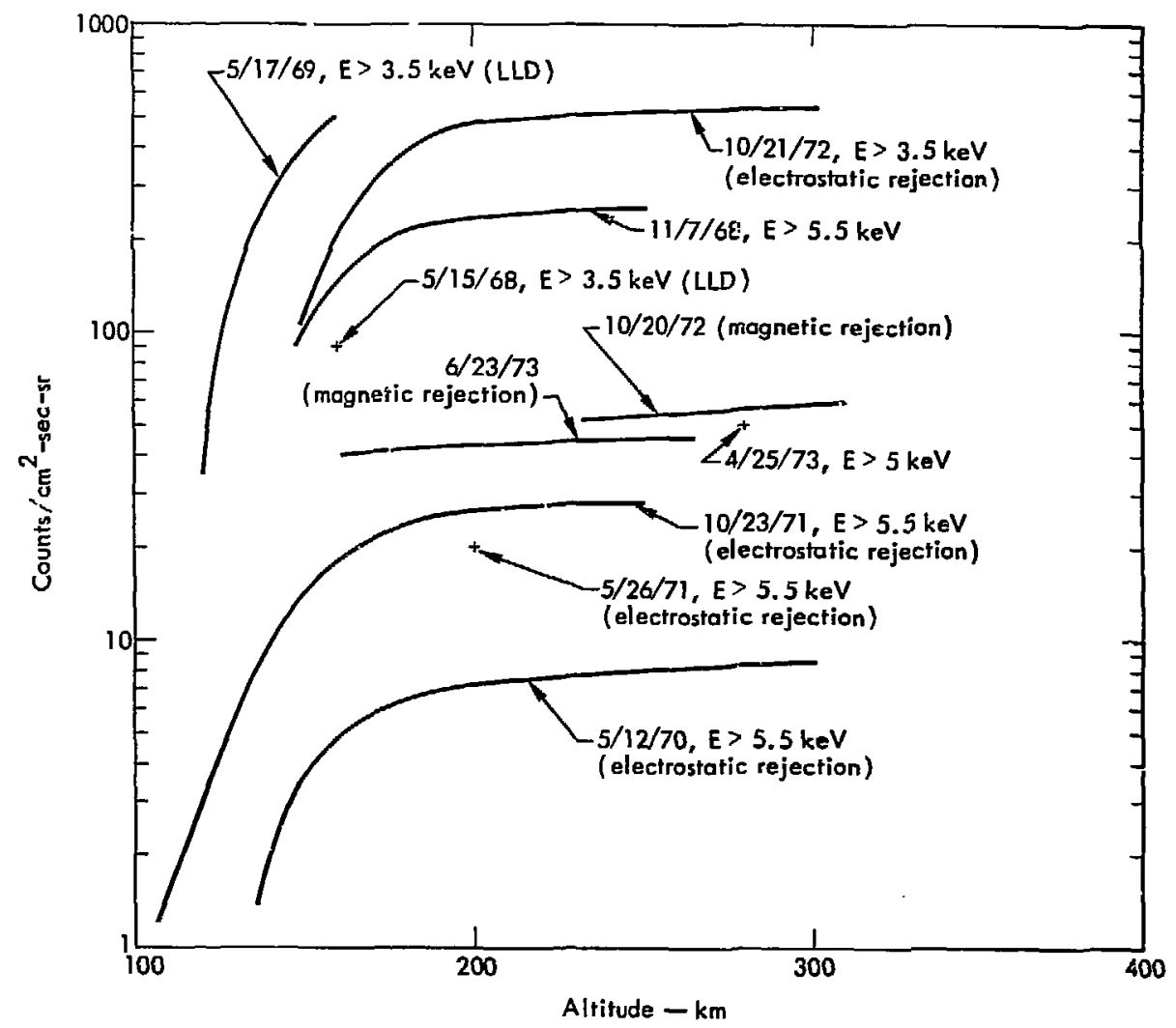

Fig. 7. Altitude dependence of parallel electrons as observed on ten flights (ULD data except where marked LLD).

most clearly. Electrons between the LLD and the ULD are sometimes difficult to see in the rapidly varying $x$-ray counting rate.

To determine the energy spectrum of the incident electrons we consider each rocket to give an integral energy spectrum measurement. The counter only detects electrons with energies above a threshold determined by the thickness of the window and the discriminator energy threshold. We used the range-energy relations of Kanter ${ }^{3}$ and Nelms ${ }^{4}$ to calculate these energy thresholds. The material was usually carbon since counter windows were Formvar and front counters were filled with methane or propane. Some of our detectors were multilayer counters, and the effective window for the back counter was a layer of Formvar, methane, and Mylar.

The range-energy curves me used are shown in Fig. 8. The energy defined by these range curves is close to the onset 
of detector window transmission. The counters are barely able to detect electrons at this threshold energy. If electron energy is increased by a factor of about 1.5 above this threshold, the counter efficiency becomes about 50\%.

To derive an energy spectrum, we have plotted in Fig. 9 the maximum observed electron counting rate as a function of threshold energy for several rocket flights. Only perpendicular electron fluxes are snown. These data were obtained with collimators having no electron rejection. Most of the points were obtained at times of high solar activity. Consequently the flux represented is high. Some of the data points have been corrected to $300 \mathrm{~km}$ using the altitude dependence discussed previously.

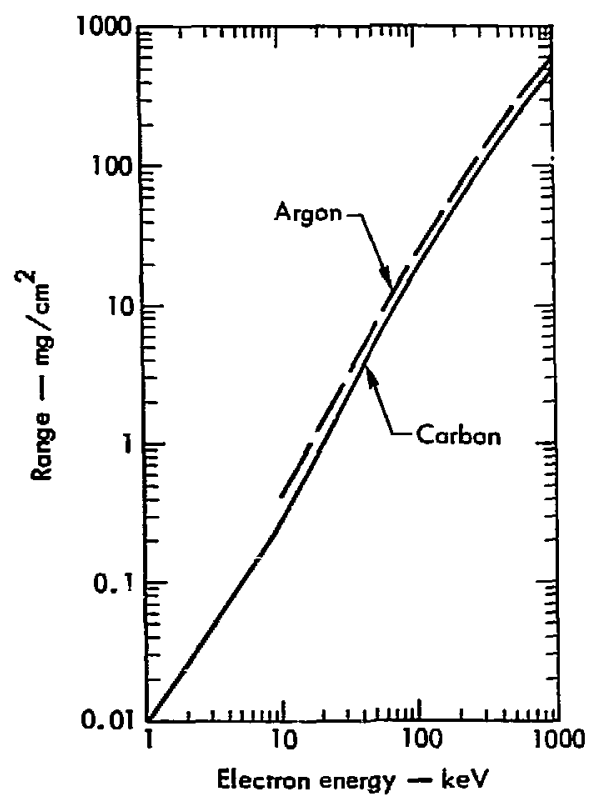

Fig. 8. Range-energy curves used in the electron energy calculations.
The line drawn through the points is describea by

$$
\begin{aligned}
N\left(E>E_{t}\right)=1.6 \times 10^{4} E^{-2.1} \text { count } \bar{s} / \\
\mathrm{cm}^{2}-\sec -\mathrm{sr},
\end{aligned}
$$

where $\mathrm{N}$ is the number of counts in the detector, and $E$ and $E_{t}$ are respectively the electron energy and the threshold energy in keV. To convert this to electron flux, one must divide by the counter efficiency, which is not well known. In the absence of more definite information the number 0.5 is recommended.

\section{FLUX VARIATION WITH SOLAR ACTIVITY}

Several hours after a large solar flare, the ejected solar plasma strikes the earth's magnetosphere. The earth's magnetic field is consequently compressed, which shows as a sudden increase in the

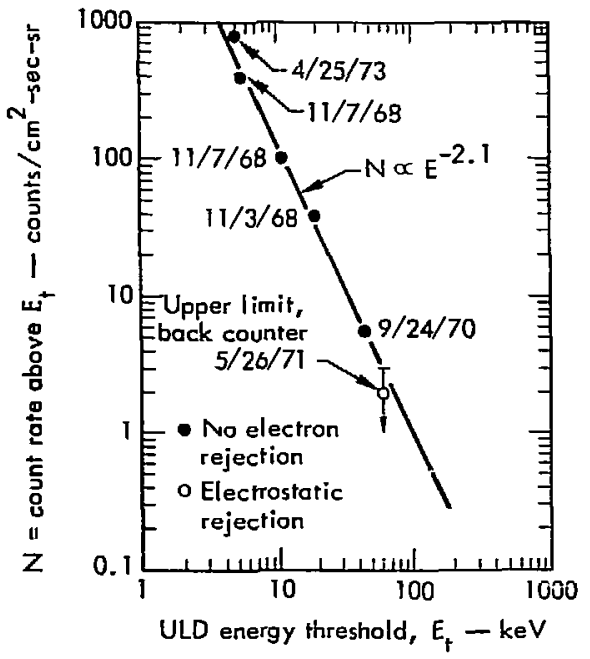

Fig. 9. Derived energy spectrum for perpendicular electrons at $300 \mathrm{~km}$. 

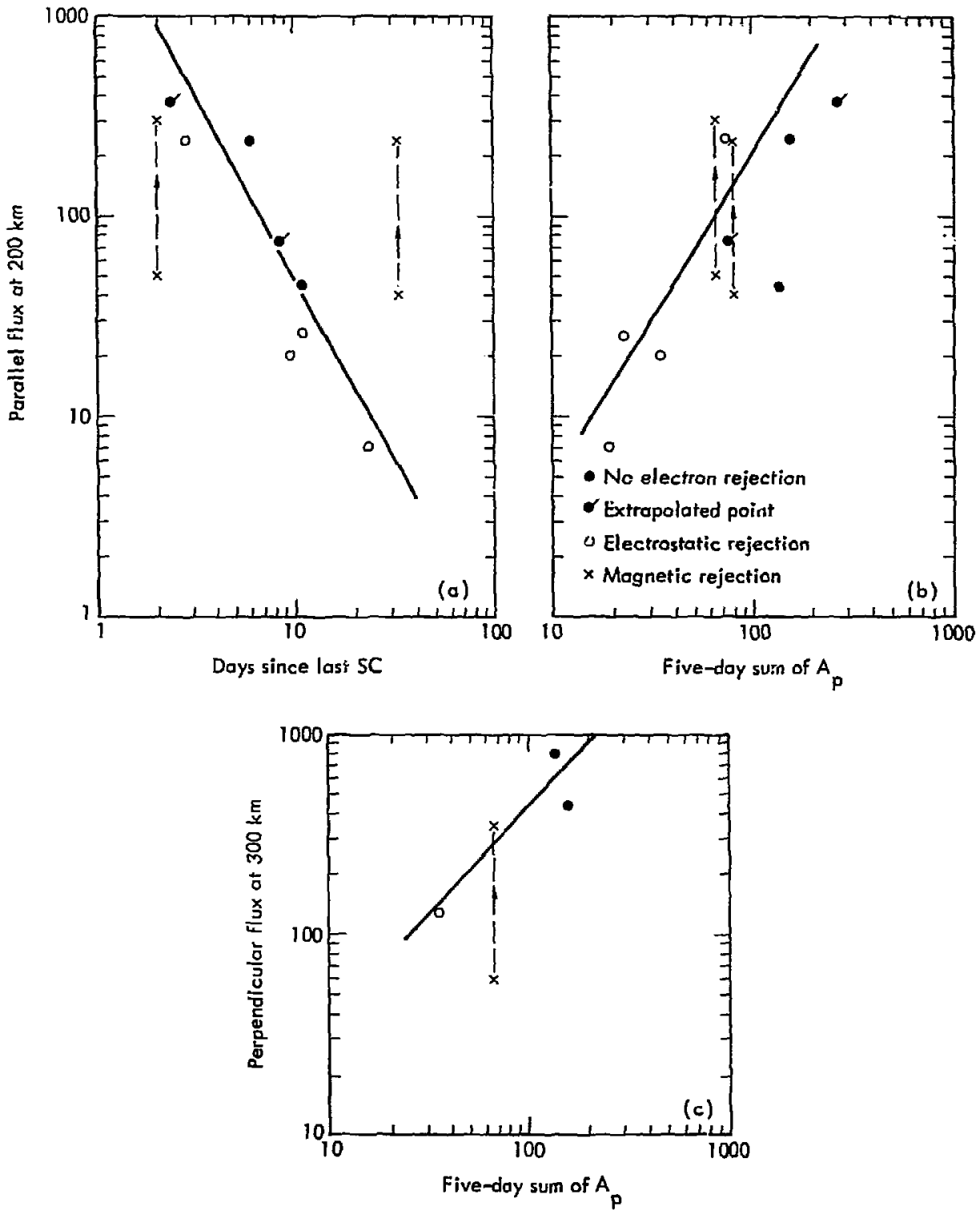

Fig. 10. Variation of electron flux with magnetic storms caused by solar flares. $\mathrm{E}>5 \mathrm{keV}$. 
eartl's magnetic field at sea level. This

"sudden commencement" (or SC) signals the beginning of a magnetic storm, a period lasting a week during which the disturbed particle currents in the magnetosphere cause additional fluctuations in the field measured at sea level.

There is a correlation of the electron flux with solar activity. This is illustrated in Fig. 10 by comparing the observed flux with magnetic activity. Straight lines have been drawn to roughly show the effect.

Figure 10(a) shows our parallel electron data plotted as a function of the elapsed time between the rocket flight and the last sudden commencement. The most intense parallel electron fluxes are observed during the first few days of the magnetic storm. These electrons are precipitating into the earth's atmosphere. Figure 10(a) shows parallel electron flux (E $>5 \mathrm{keV}$ ) at $200 \mathrm{~km}$ altitude. Two lower altitude flights have been extrapolated to $200 \mathrm{~km}$ using the observed altipide dependence. The electrostatic collimator points can probably be compared directly with those points taken with collimators having no electron rejec- tion. Two data points taken with magnetic collimators have been increased by a factor of 6 since this is our estimate of the minimum rejection efficiency of this collimator. Thus many of the data points have been adjusted. Since varying geomagnetic phenomena are in any case imprecise, we feel this procedure is justified.

Figure 10(b) displays these data in a different fashion. The observed parallel electron flux bas been plotted as a function of magnetic activity. The average daily planetary magnetic field index, ${ }^{A} p$, has been summed for the five days preceding the launch. The observed data has been plotted as a function of this five-day sum of $A_{p}$. Since $A_{p}$ is large irnmediately following a sudden commencement, the two plots are almost equivalent.

The perpendicular electron flux also varies with magnetic activity. Figure $10(\mathrm{c})$ shows the few perpendicular electron measurements that we have. The flux increase with magnetic activity is apparently not as great for perpendicular electrong as for parallel electrons.

\section{Results in Relation to the Geophysical Environment}

This section is a discussion of particle motion over the Kauai Range. Data in this report were taken from three launch sites: Kauai, Johnston Island, and a site located at $27 \mathrm{~N}^{\circ} 125^{\circ} \mathrm{W}$. Although magnetic field conditions are slightly different, basic features are similar for all three locations.

At great altitudes, electrons are constrained to move about magnetic field lines. An electron moving parallel to the field plunges directly into the earth's atmosphere, loses its energy, and is stopped. An electron having a velocity vector making a large angle with the magnetic field vector and traveling down toward the earth will "mirror" as the magnetic field strength increases; i.e., it will be reflected back up the field line. The motion of such an electron consists 
of a fairly rapid bouncing between mirror points, back and forth along the field line, coupled with a slow drift to tire east. If the mirroring altitude is high enough, this eastward drift will carry the electron completely around the earth. During this drift, although moving from one field line to another, the electron is constrained to remain in a specific magnetic shell characterized by the parameter $L$. ( $L$ in a pure dipole field is the maximum distance a field line extends from the center of the earth, measured in earth radii.) The motion of an electron in the earth's magnetic field is completely determined by the $L$-value of the magnetic shell and the value of the magnetic field, $B$, at its mirror points. These two items can be treated as invariants of motion.

At an altitude of $300 \mathrm{~km}$ above the Kauai Range the magnetic coordinates are $L=1.20, B=0.32 \mathrm{G}$. An electron mirroring at $300 \mathrm{~km}$ altitude above Kauai mirrors at an altitude of $500 \mathrm{~km}$ at the southern hemisphere conjugate point and has an altitude of $1200 \mathrm{~km}$ as it travels (along the field line) through the magnetic equator. These electrons cannot drift all the way around the earth on this $L$ shell. The mirror point altitude as the electron goes east decreases and descends into the dense atmosphere. Thus, electrons observed mirroring (moving perpendicular to the field line) at $300 \mathrm{~km}$ above Kauai cannot be permanently trapped in the earth's field but are at most quasitrapped.

The times for an electron to bounce between mirror points and to drift around the world have been calculated by Hamlin et al. ${ }^{5}$ and by Lew. ${ }^{6}$ A 100-keV electron mirroring at $300 \mathrm{~km}$ above Kauai has a bounce period of $0.16 \mathrm{sec}$ and a drift period of $5 \mathrm{hr}$ (if it were possible to drift around the earth without descending into the atmosphere). At the mirror point the electron has a trajectory with a radius of curvature of $33 \mathrm{~m}$ and takes $: .3 \mu \mathrm{sec}$ to make a revolution around the field line.

The presence of the atmosphere greatly modifies the behavior of electrons in this region. Electrons scatter and lose energy in the atmosphere. When a mirroring electron is scattered it assumes a trajectory that lowers the mirror point to a region where the atmosphere is denser; thus further scattering is more probable, the mirror point lowering is accelerated, and the electron is soon on a trajectory where it descends deep enough to be lost. Over the Kauai Range the chance of scattering is determined by the atmospheric density over Kauai, since this mirror point is lower than the corresponding mirror point in the southern hemisphere. Atmospheric density varies greatly with solar activity and time of day. We have salculated the densities for an atmosphere with average Eolar activity (CIRA No. 5$)^{2}$ at 22:00 local time. Deviations from these values are expected to be on the order of a factor of 2 .

If an electron has traversed an amount of material equal to $1 / 100$ of its range it will have been scattered through an angle of about $10^{\circ}$. We have calculated the altitude at which an electron of given energy, mirroring at that altitude, might be expected to encounter this amount of material. Curves have been drawn in Fig. 11 to illustrate the expected behavior. The highest curve corresponds to an energy where it takes 100 bounces between mirror points to traverse this 


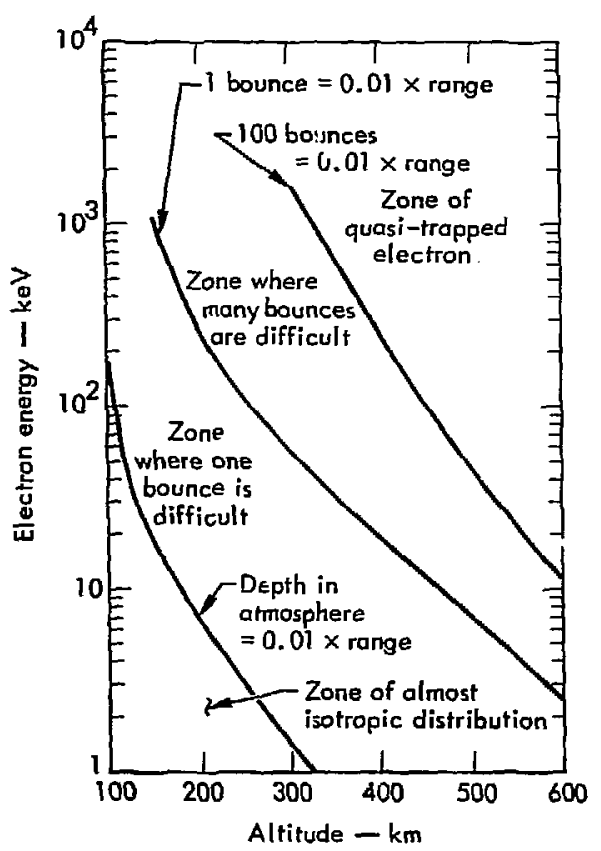

Fig. 11. Expected electron behavior over Kauai. Electron energy is plotted vs altitude for various effective depths in the atmosphere.

amount of atmosphere. Thus, the mirror motion should be relatively stable at altitudes above or at energies higher than this curve. The next lower curve shows the energies where the electron is ex- pected to be scattered a few degrees in anly one bounce. Mirroring electron should not persist below this curve. he bottom curve shows altitudes at which electr ons moving parallel to the field lines have traveled through an atmospheric thickness of $1 / 100$ of their range. Below this curve the electron flux should be almost isotropic.

As an illustration, at $300 \mathrm{~km}$ altitude, electrons having energies of $\sim 1 \mathrm{MeV}$ are able to mirror many times without much scattering. As the energy is decreased to below $\sim 100 \mathrm{keV}$, electrons are appreciably scattered during one mirror oscillation, and thus mirroring electrons should not be observed strongly below this energy.

When mirroring electrons are observed at low aititude they appear as a distribution peaked at a direction corresponding to velocities perpendicular to the field line. We have observi 1 distributions like this in several flights in the altitude range 200 to $300 \mathrm{~km}$. Figure 11 indicates that these electrons must have energies of $\sim 100 \mathrm{keV}$ or more. Our measured in-flight collimator transmission of $4 / 25 / 73$ also implies an effective electron energy of $>100 \mathrm{keV}$, which is in agreement with this anaiysis.

\section{Electron-Rejecting Collimators to Reduce the Background}

We have so far discussed the number of electrons penetrating into the counter by referring to the counting rate above the ULD. Thus, the rates shown in Figs. 4-10 are all from ULD data. Electron-induced counts also appear between the LLD and the ULD. These counts are due to events which deposit only a small amount of energy in the counter gas. Such events are not caused by high energy electrons passing through the detector. They are probably due to low energy electrons scattered from the collimator into the counter or to $x$ rays generated by electrons striking the collimator. 
The pulse height spectrum of eyents induced by low energy electrons always has approximately the same form, dN/dE $\propto \mathrm{E}^{-1}$, which is illustrated in Fig. 12. The expected primary electron spectrum is more like $\mathrm{dN} / \mathrm{dE} \propto \mathrm{E}^{-3}$ (derived from data of Fig. 9). Thus, we consider the low energy spectrum to contain little information about the primary electron spectrum. The low energy events, howEver, are the ones we want to eliminate. If all electron events were to appear only above the ULD there would be no background problem.

Table 2 lists some flight data in which we have been able to clearly distinguish electron-induced erente: in the $x$-ray data. The table shows the electron-induced background at $1 \mathrm{keV}$ relative to the total number of electron counts depositing more than $5 \mathrm{keV}$ in the detector. Specifically, we define the relative number of low energy events to be

Electron-induced counts/sec-keV at $1 \mathrm{keV}$ Electron-induced counts/ses. above ULD ( $\geq 5 \mathrm{keV})$
The relative induces background in Table 2 varies according to the type of collimator used. A plain aluminum surface seems to give the highest relative background. Plain copper is lower and rough paint or rough EDM (electricdischarge-machined) aluminum are also low. Labcratory measurements of electron rejection show a similar dependence on collimator material. There is no structure in the electron-induced low energy spectrum that might indicate characteristic $x$ rays from the collimator. Thus, the most likely source of these low energy events is low-energy scattered electrons.

\section{THEORY}

We have used both electrostatic and magnetic fields to sweep electrons into the collimator walls. The fields were applied so that electrone were swept into the walls across the narrowest collimator dimension. If we assume that electrons entering the collimator are eliminated after one collision with a wall, i.e., that

Table 2. Relative number of low-energy electron eventa observed on eight flights with various collimator vane materials and electron rejection schemes.

\begin{tabular}{lllc}
\hline Flight date & \multicolumn{1}{c}{$\begin{array}{c}\text { Collimator } \\
\text { vanes }\end{array}$} & $\begin{array}{c}\text { Electron } \\
\text { rejection }\end{array}$ & $\begin{array}{c}\text { Relative number of } \\
\text { low energy events }\end{array}$ \\
\hline $5 / 15 / 68$ & Painted & None & 0.24 \\
$11 / 7 / 68$ & Aluminum & None & 0.84 \\
$5 / 17 / 69$ & Painted & None & 0.25 \\
$5 / 26 / 71$ & Copper & Electrostatic & 0.16 \\
$5 / 20 / 72$ & Aluminum & Magnetic & 0.66 \\
$10 / 20 / 72$ & Blackened copper & Magnetic & 0.30 \\
$10 / 21 / 72$ & Copper & Electrostatic & 0.14 \\
$6 / 23 / 73$ & EDM aluminum & Magnetic & $<0.10$ \\
\hline
\end{tabular}

\footnotetext{
${ }^{a} E D M=$ electric-discharge-machined.
} 


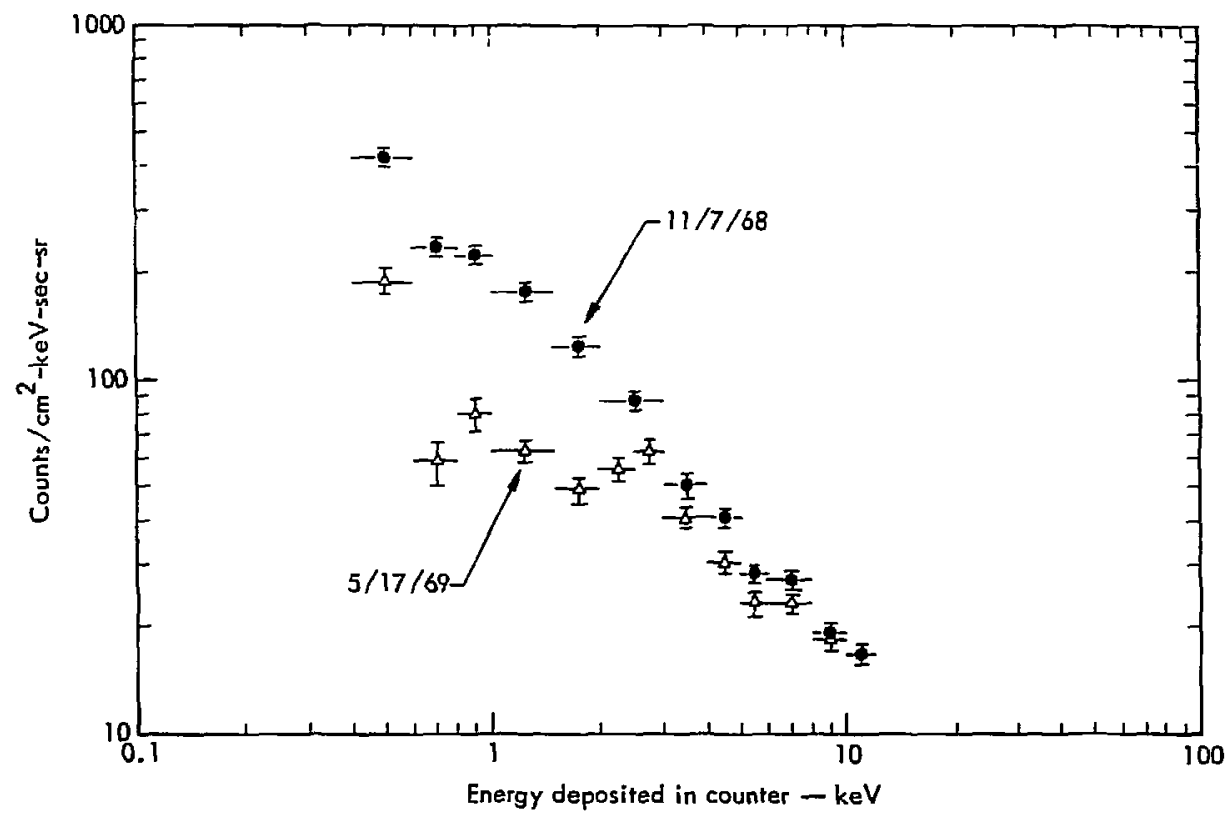

Fig. 12. Pulse height spectrum of events induced by low energy electrons.

there is no scattering, then a collimator section of length $\ell \mathrm{cm}$ and width $\mathrm{d} \mathrm{cm}$ will reject all electrons with energies less than a cutoff energy, $\mathrm{F}_{\mathrm{c}}$.

Electrostatic electron rejection. The applied potential in volts is

$$
V=\frac{16 d^{2} E c}{l^{2}+16 d^{2}}
$$

vhere $\mathrm{E}_{\mathrm{c}}$ is in $\mathrm{eV}$.

Magnetic electron rejection. The critical radius of curvature is

$$
\rho_{c}=\frac{4 d^{2}+\ell^{2}}{8 d}
$$

and

$$
B \rho_{c}=3336\left(E_{c}^{2}+1.02 E_{c}\right)^{1 / 2},
$$

where $B$ is in gauss $(G), \rho_{c}$ in $\mathrm{cm}$, and $\mathrm{E}_{\mathrm{e}}$ in $\mathrm{MeV}$.

We know, however, that these considerations are too simple in assuming no scattering. The angles of incidence are only 1 or $2^{\circ}$, so electrons scatter easily from the collimator walls. Therefore, to be pessimistic, the cutoff energy can be calculated allowing a single scattering in which energy loss is negligible. In this case, the cutoff formulae become

$$
V=\frac{64 d^{2} E_{c}}{64 d^{2}+2^{2}}
$$




$$
\rho_{c}=\frac{16 \mathrm{~d}^{2}+Z^{2}}{32 \mathrm{~d}}
$$

Using typical collimator dimensions of $\mathrm{d}=0.10$ in. and $\ell=2.5$ in., we have calculated (Table 3 ) the required electrostatic and magnetic fields for the noscattering and single-scattering assumptions (see Fig. 13).

\section{FLIGHT TESTS}

Figures 2, 14, and 15 show flight data taken with electron-rejecting collimators. The collimator of Fig. 2 had a field of view of $6^{\circ} \times 7^{\circ} \mathrm{FWHM}$ and contained a magnetic field of about $100 \mathrm{G}$. Calculated no-scattering and single-scattering cutoffs were at 41 and $3.3 \mathrm{keV}$, respectively. The in-flight transmission of this collimator for perpendicular electrons was 0.15 . (This can be obtained directly from Fig. 2.)

Figure 14 shows data taken with an electrostatic collimator. The detector was first oriented to point directly up the field line and the collimator voltage was stepped to 0,200 , and $700 \mathrm{~V}$. This was repeated later in the flight with the detec- tor pointing perpendicular to the earth's magnetic field. (Calculated no-scattering and single-scattering cutoff energies are 0,11 , and 38 , and 0,3 , and $10 \mathrm{keV}$, respectively.) The collimator transmission was 1.0 and 0.8 at the two applied voltages when pointing parallel to the field and 1.0 at both voltages when pointing perpendicular to the field.

With $700 \mathrm{~V}$ applied, the counting rate in the $x$-ray window became high. If the electron potential is above $280 \mathrm{~V}$, carbon $\mathrm{K} \mathrm{x}$-rays are generated when ionospheric electrons (density $10^{4}-10^{5} / \mathrm{cm}^{3}$ at thermal energies) are accelerated into the collimator walls. Thus, electrostatic collimators cannot be used with applied fields above $280 \mathrm{~V}$. Since not many electrons are rejected at this potential, the electrostatic collimator is not a good system to use.

Figure 15 (and also Fig. 1) shows data taken on a different flight with the same detector but with a magnetic collimator with calculated cutoffs at 53 and $3.6 \mathrm{keV}$. The electron background is much lower. If we assume the primary electron flux unchanged (the five-day sums of $A_{p}$ are very close), the magnetic collimator transmission was $\sim 0.20$.

Table 3. Calculated electrostatic and magnetic fields required for the assumptions of no scattering and single scattering of electrons from the collimator vanes. Vane dimensions are $d=0.10$ in. and $l=2.5$ in. (see Fig. 13).

\begin{tabular}{ccccc}
\hline $\begin{array}{c}\text { Cutoff energy, } \\
\mathrm{E}_{\mathrm{c}}(\mathrm{keV})\end{array}$ & $\begin{array}{c}\text { Electrostatic field (V) } \\
\text { With no } \\
\text { scattering }\end{array}$ & $\begin{array}{c}\text { With single } \\
\text { scattering }\end{array}$ & $\begin{array}{c}\text { Magnetic field (G) } \\
\begin{array}{c}\text { With no } \\
\text { scattering }\end{array}\end{array}$ & $\begin{array}{c}\text { With single } \\
\text { scattering }\end{array}$ \\
\hline 10 & 250 & 930 & 17 & 65 \\
30 & 750 & 2800 & 30 & 115 \\
100 & 2500 & 9300 & 56 & 220 \\
300 & 7500 & - & 105 & 410 \\
\hline
\end{tabular}




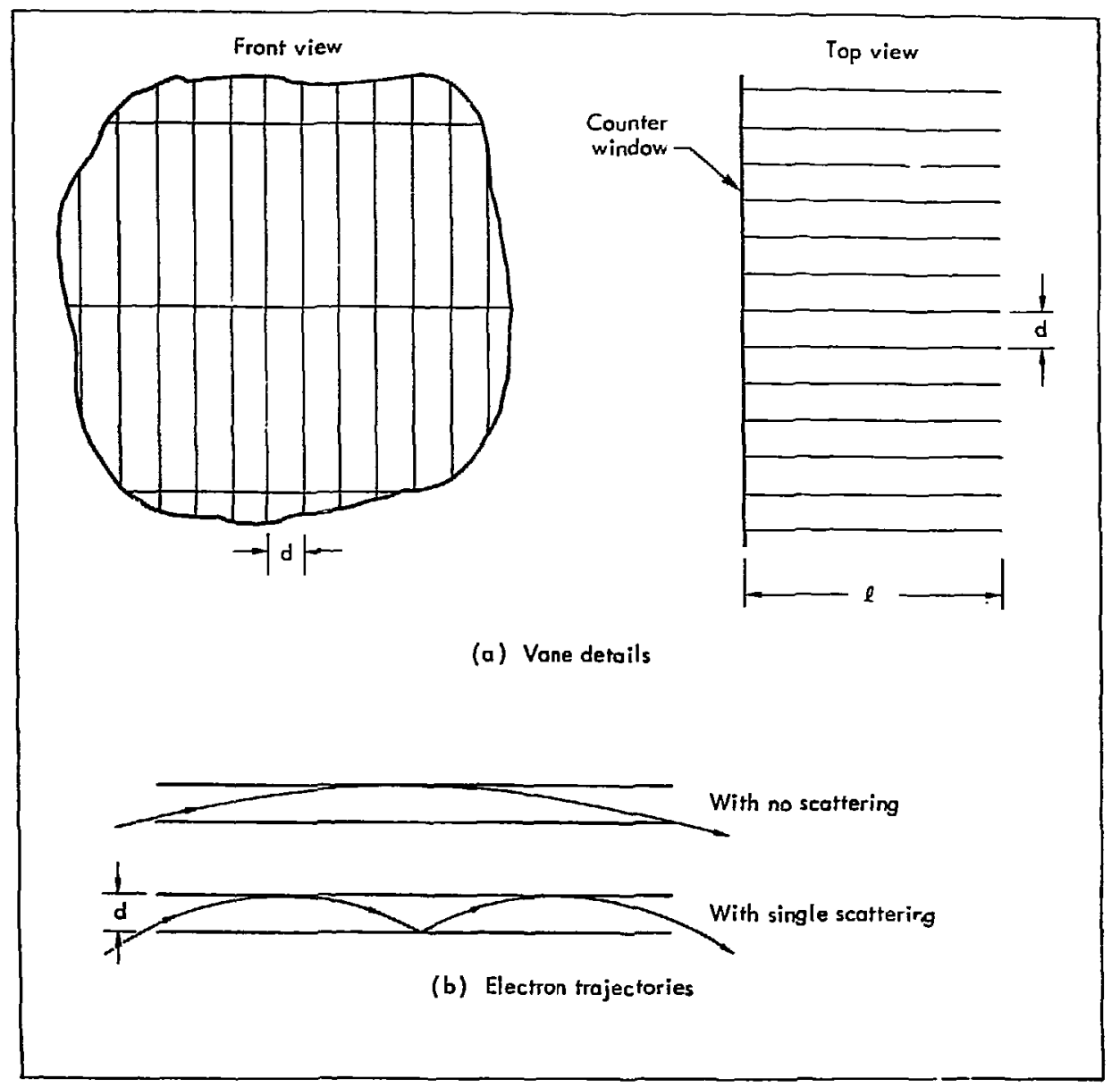

Fig. 13. Vane details of an electron-rejecting collimator. (a) Front and top views of a portion of the vanes. (b) Trajectories through the vanes assumed for an electron of energy $\mathrm{E}_{\mathrm{c}}$ with no scattering and with a single scattering.

\section{LABORATORY TESTS}

We have measured the electron transmission of collimators in the laboratory. Our goals were first to understand the measured in-flight transmissions and then to study collimators constructed of different materials.
Electron sources used were ${ }^{63} \mathrm{Ni}$ and ${ }^{90}$ Sr. Nickel 63 emits a continuous spectrum of electrons having an end-point energy of $65 \mathrm{keV}$. The ${ }^{90} \mathrm{Sr}$ source emits electrons equally from both ${ }^{90} \mathrm{Sr}$ and ${ }^{90} \mathrm{Y}$. The end points of the $\beta$ spectra are $540 \mathrm{keV}$ and $2.2 \mathrm{MeV}$.

The experimental apparatus consisted of a small stainless steel proportional 


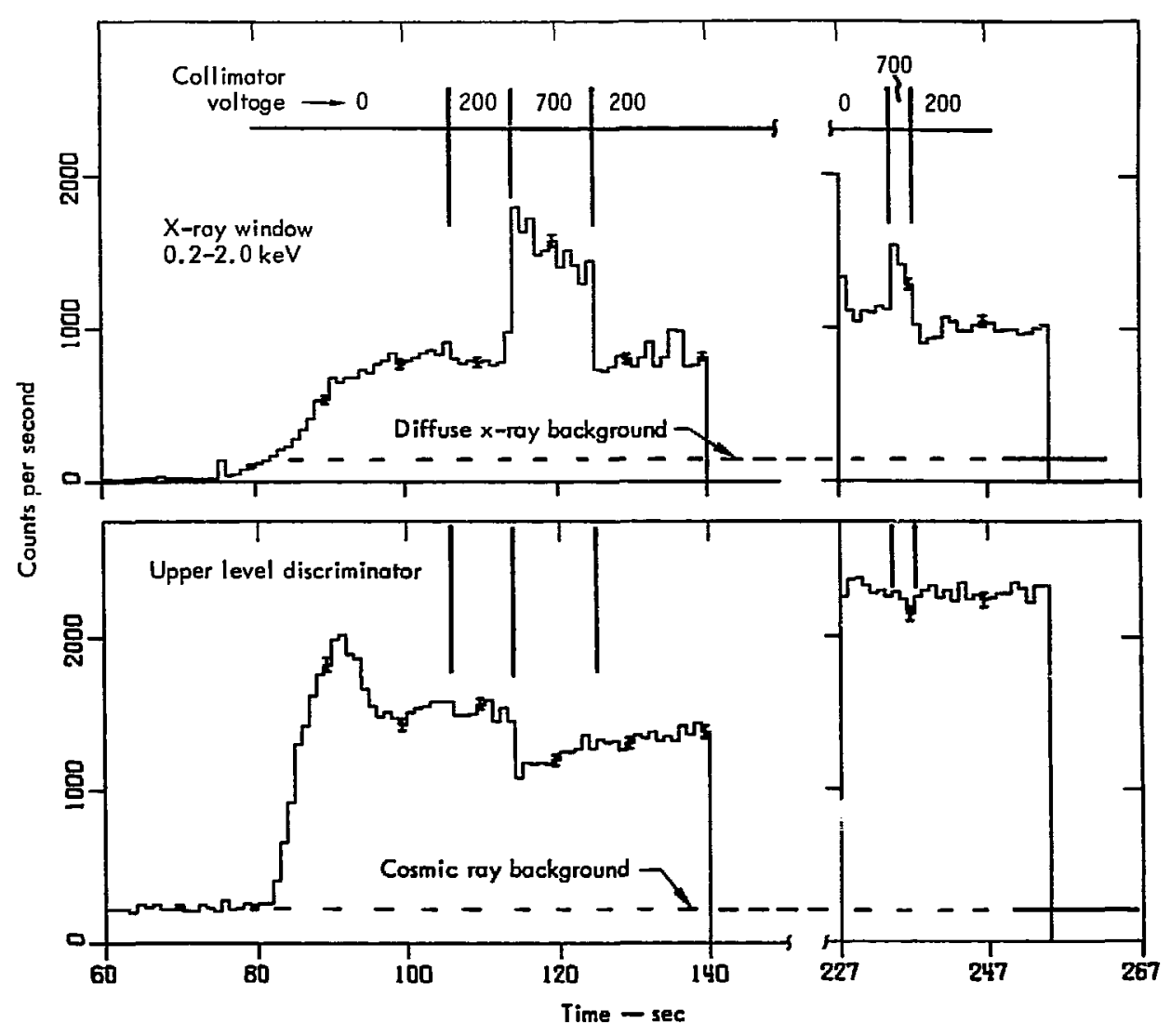

Fig. 14. In-flight test of a collimator with electrostatic electron rejection made on October 21, 1972.

counter with a $30-\mu \mathrm{g} / \mathrm{cm}^{2}$ Formvar window operating with propane gas at $100 \mathrm{~mm}$ Hg absolute pressure. The counter was constructed so that selected collimators could be placed over the thin window and tested with ceramic-slab permanent magnets of various strengths. The electrons were collimated to illuminate a region slightly larger than the counter collimator area. High intensity magnets of 800-G field could be placed next to the source-collimator to "shut off the electron beam for background measurements. Figure 16 shows a schematic of the experimental geometry. This apparatus tvas placed in a vacuum tank and operated at $\sim 10^{-5}$ Torr.

The ${ }^{63}$ Ni source was essentially $x$-ray-free between the nickel $L$ and $K$ edges, enabling us to achieve electron counting rates of 150 times background in the range from $1 \mathrm{keV}$ to counter saturation a: $5 \mathrm{keV}$. The ${ }^{90} \mathrm{Sr}$ source produced a large $x$-ray flux below $6 \mathrm{keV}$ which 


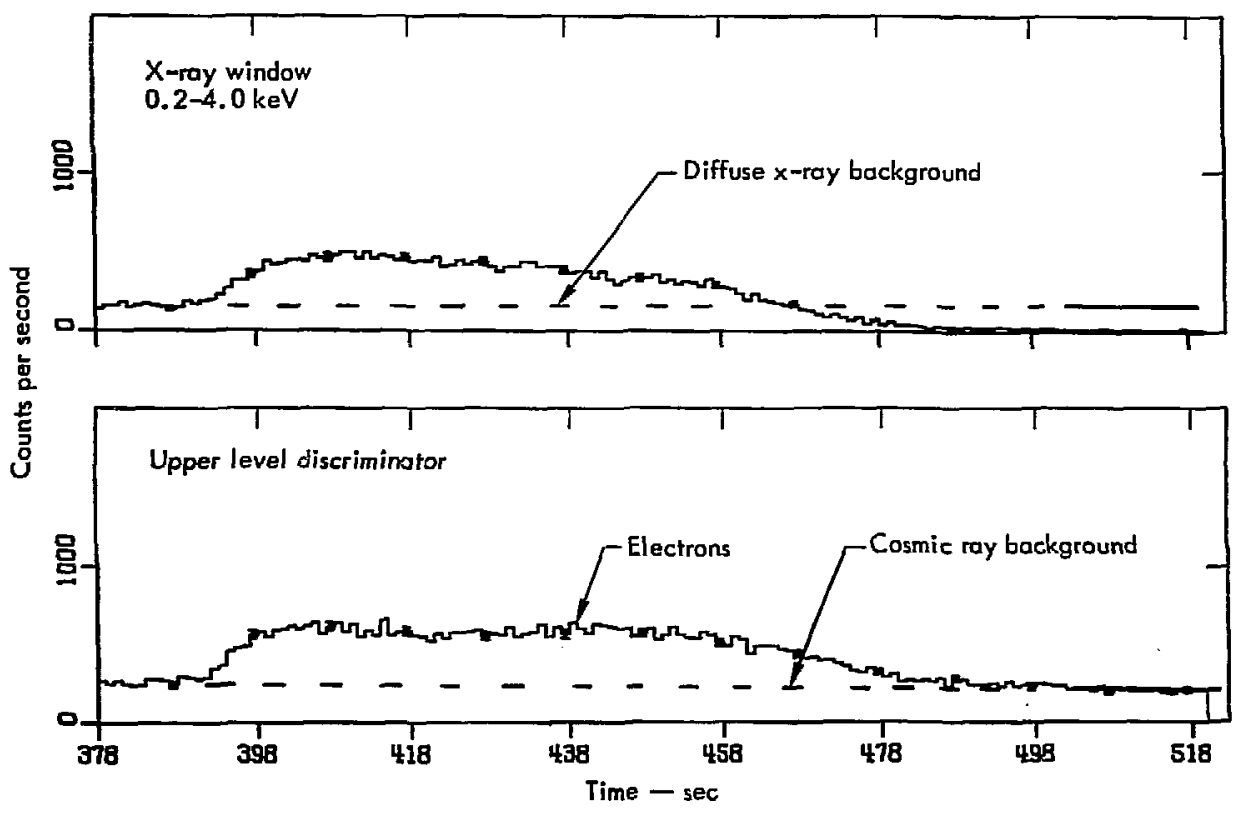

Fig. 15. Data from a detector and collimator with magnetic electron rejection flown May 20, 1972.

masked all low-encrgy electron events in the counter.

The transmission of each collimator was measured by first taking the initial count rate with no sweep magnets on the collimator or the source-collimator. Next the collimator magnets were ingtalled and the count rate measured for several field atrengths. Finally, the source-collimator magnets were used to shut off the electron beam and obtain the background due to natural radioactivity and $x$ rays from the electron source.

The rocket night of $4 / 25 / 73$ carried two honeycomb-type collimators. One contained magnets and was electronrejecting, the other was not. The inflight measured electron transmission was 0.15 (this is shown in Fig. 2). The laboratory-measured transmission of this collimator was 0.02 for ${ }^{63} \mathrm{Ni}$ electrons and 0.45 for ${ }^{90} \mathrm{Sr}$ electrons. Thus, the ${ }^{90} \mathrm{Sr}$ electrons, $50 \%$ of which have energies above $0.4 \mathrm{MeV}$, are more energetic than those encountered in flight, while the ${ }^{63} \mathrm{Ni}$ electrons, with $65 \mathrm{keV}$ maximum energy, are not energetic enough to reproduce the flight environment.

Even though neither source duplicates the natural electron spectrum, they can both be used to measure the relative transmissions of collimators made from different materials. We have made such measurements to find a material which will minimize electron scattering in the 


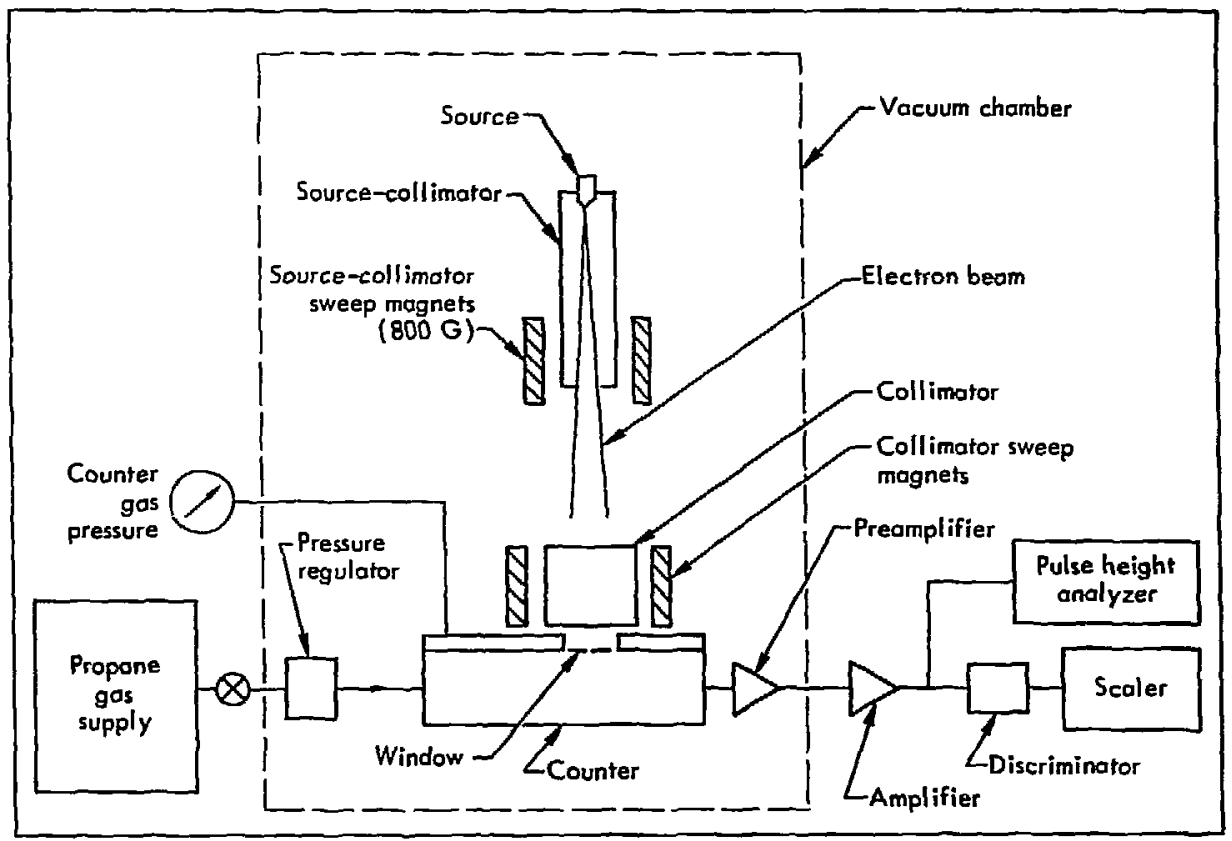

Fig. 16. Schematic of the laboratory apparatus for measuring electron transmission by a collimator.

collimator. For this purpose a series of slat-type collimator samples was constructed. All were of the same dimensions with collimator angle of $2^{\circ} \times 12^{\circ}$ FWHM. The only parameter varied was the surface roughness of the vanes. The vanes were made with polished aluminum, expanded metal (aluminum sheet perforated with 1/8-in. holes), EDM aluminum (electric-discharge-machined), 100-line woven aluminum screen, and copper.

The variation of electron transmission with the strength of the magnetic sweep field is shown in Fig. 17 for ${ }^{63} \mathrm{Ni}$ and ${ }^{90} \mathrm{Sr}$ electrons. Here the effect of collimator surface roughness is apparent in the consistently lower transmission for the EDM and screen collimators. Figure 18 shows the measured transmission of the electrostatic collimator. The vanes of this collimator were of copperplated Synthane (printed circuit board material).

Figure 19 shows selected laboratorymeasured transmissions plotted as a function of calculated no-scattering collimator cutoff energy. Note the appreciable transmission above the end-point energy of the ${ }^{63} \mathrm{Ni}$ source. These are scattered electrons, as is obvious from the lower transmission with the rough EDM collimator vanes. The tlightmeasured transmissions are higher, indicating more energetic electrons. 


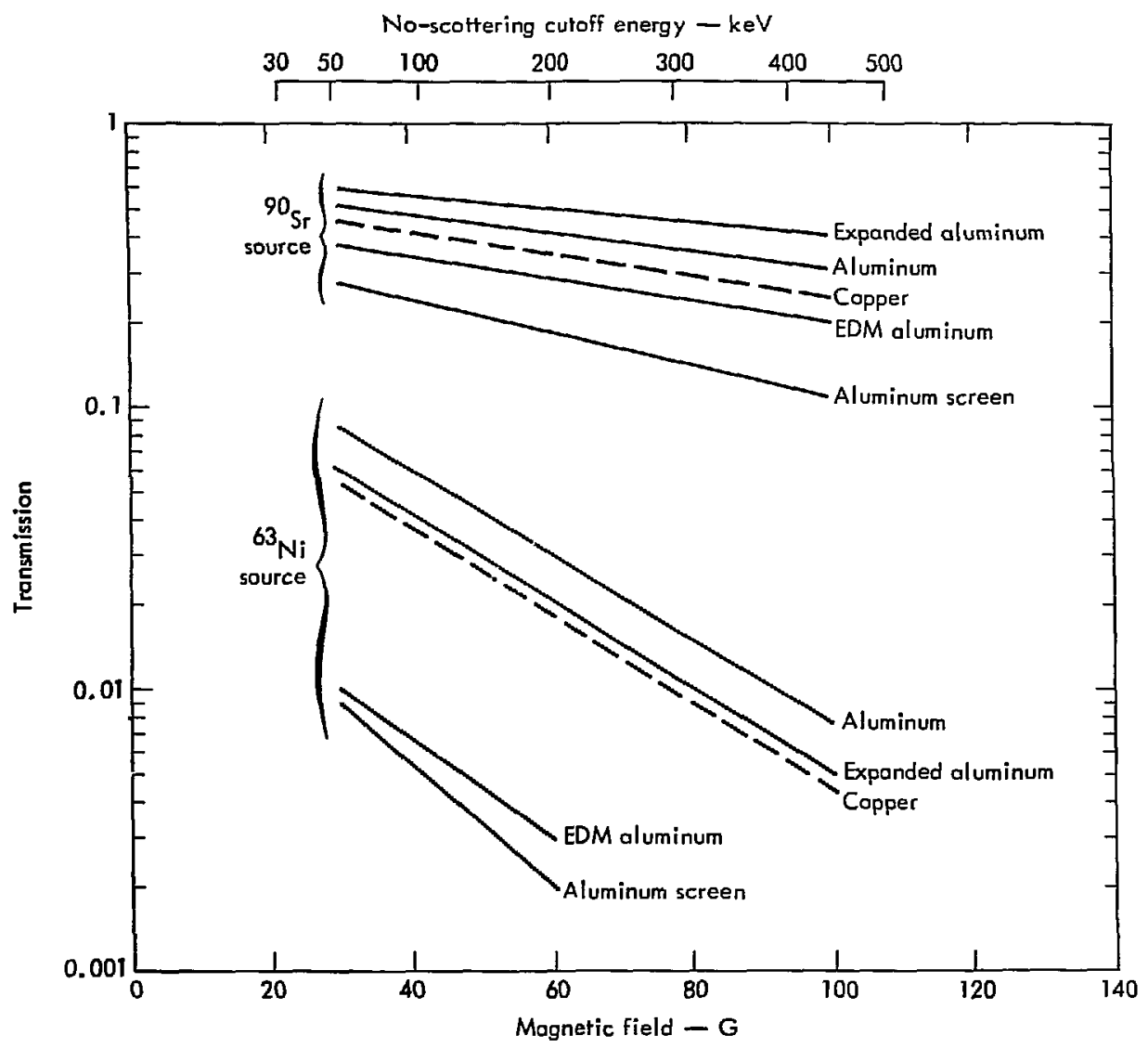

Fig, 17. Laboratory measurements of electron transmission by a collimator with magnetic electron rejection.

\section{RECOMMENDATIONS FOR}

\section{A GOOD COLLIMATOR}

We draw the following conclusions concerning electron-rejecting collimators:

1. Electrostatic collimators are impractical. It is a nice feature to be able to turn them off and on in flight; but electron energies are high, requiring a high applied potential, and the consequent generation of soft $x$ rays in the collimator creates more background counts than the collimator rejects.
2. For a magnetic collimator, the field should be as high as possible so electron rejection is at a maximum.

3. Rough-surfaced vanes are necessary to minimize electron scattering and reduce transmission. We found the construction of an alumimm screen collimator too difficult, so we are using EDM collimators for future flights.

4. Collimators with large open areas in the vanes do not reject high-energy 


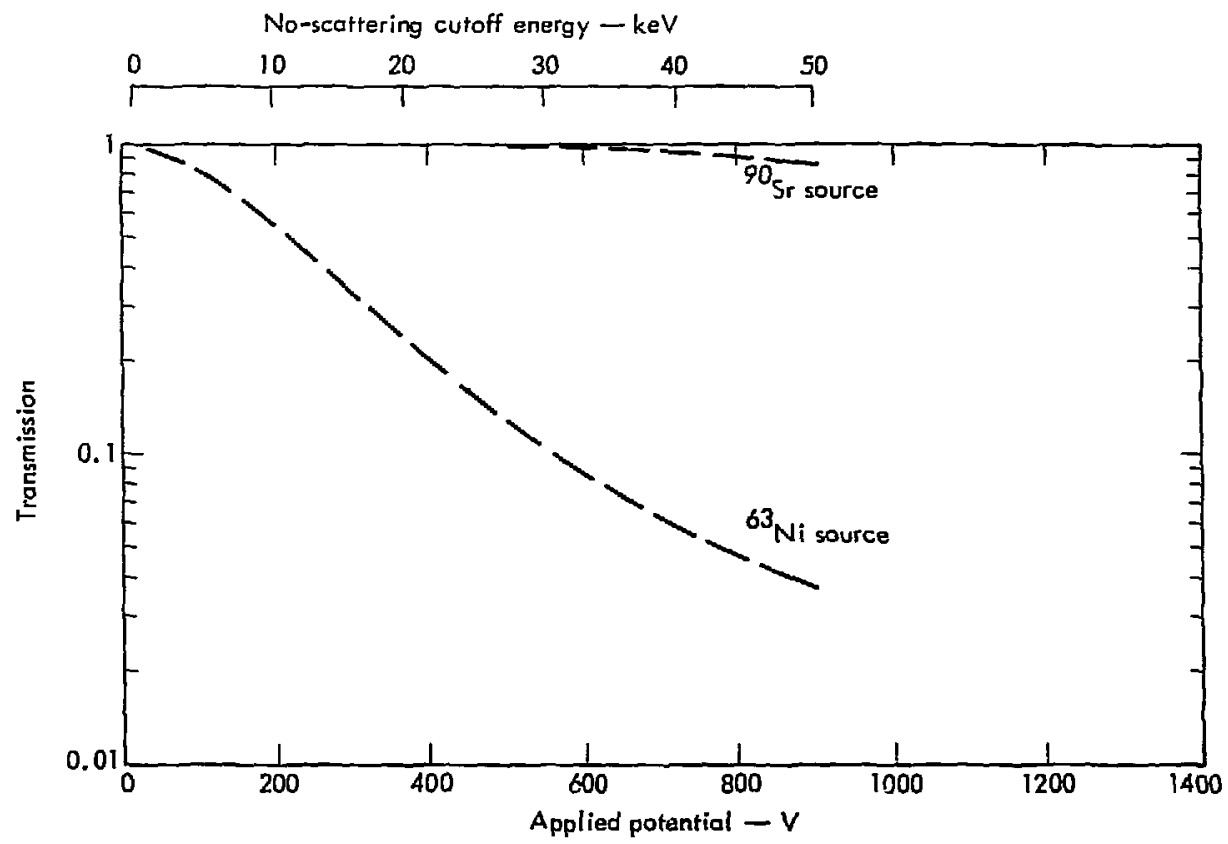

Fig. 18. Laboratory measurements of electron transmission by a collimator with electrostatic electron rejection.

electrons well. The openings permit more scattering than the solid vanes.

The best electron-rejecting collimator is one which will (1) keep the largest fraction of incident electrons out of the counter, and (2) have a low relative number of low energy counts produced by those electrons which do penetrate the collimator. It has been our experience

Fig. 19. Comparison of in-flight electron transmission with laboratory transmission measurements made with a ${ }^{63} \mathrm{Ni}$ electron source.

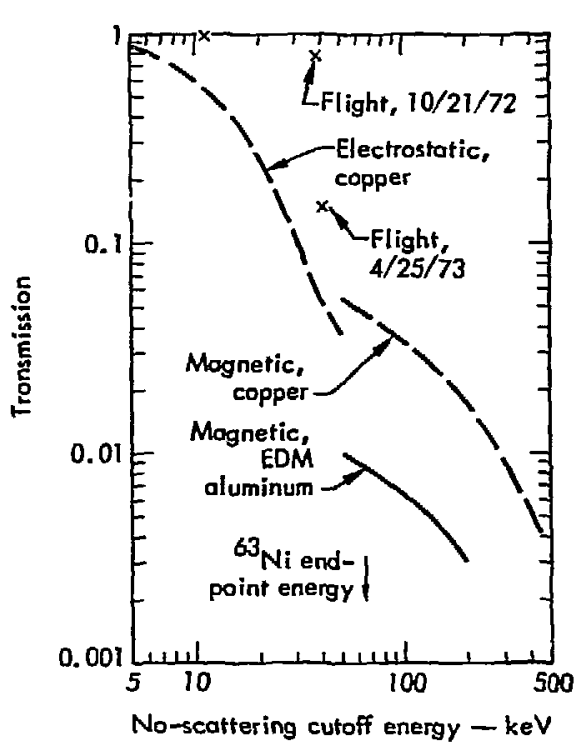


that magnetic fields produce large rejection efficiencies and that collimator vanes with a rough surface lfine sandpaper texture) increase the rejection by reducing the probability of small-angle electron scattering. A rough surface also produces relatively fewer low energy events.

Our laboratory measurements and flight data lead us to believe that the electrons above the atmosphere can be treated as having an average energy of $\sim 100 \mathrm{heV}$. If a collimator could be built to reject electrons of $100-150 \mathrm{keV}$ in the labol-atory (transmission $<10^{-3}$ ), the electron transmissions in flight would be negligible compared with the diffuse background. We think we can achieve this performance using a magnetic collimator constructed from EDM aluminum and with a field of $\sim 200 \mathrm{G}$,

\section{Predicting the Electron-Induced Background}

This report summarizes data taken with different detectors, with a variety of collimators, at different places, and at different times. We have derived, as best we could, the average characteristics of the electron flux above the atmosphere and its effect on our detectors. Our conclusions have been presented in a form hopefully useñll to $x$-ray astronomers, and they may be used to predict background rates on past and future observations. This naturally will not be a precise prediction, but a factor-of -2 accuracy might be expected Our data applies to Kauai and may be taken as typical for mid-Iatitudes. Variation with location is expected and is given very approximately by Seward. 1

The total electron-produced counting rate in a large-area proportional counter with an ordinary (10n-electron-rejecting) collimator may be predicted as follows: First, the counter threshold is calculated using the window thickness, the rangeenergy curve of Fig. 8, and the discriminator setting. Figure 9 then gives the maximum expected rate at $300 \mathrm{~km}$. The variation of flux with altitude may be predicted from Figs. 6 and 7 , and the variation with solar activity from Fig. 10, if these refinements are desirable.

To calculate the electron-induced background in the $x$-ray window, one obtains tive electron rate at $1 \mathrm{keV}$ by multiplying the predicted number of ULD events by an appropriate coefficient selected from Table 2. This coefficient will be between 0.1 and 0.8 depending on the collimator used. The spectrum induced by low energy electrons has the form dN/dE $\propto \mathrm{E}^{-1}$, where $\mathrm{E}$ is energy deposited in the counter. This can be used to predict background levels throughout the $x$-ray window.

If an electron-rejecting collimator is used, the electron background will be reduced. The in-flight rejection efficiency will nat be $a s$ good as the laboratory measurements shown in Fig. 19. The nonscattering cutoff energy of the collimator must be calculated to make this comparison, and a transmission intermediate between our ${ }^{63} \mathrm{Ni}$ and ${ }^{90} \mathrm{Sr}$ measurements can be expected. 


\section{References}

1. F. D. Seward, The Geographical Distribution of $100-k e V$ Electrons Above the Earth's Atmosphere, Lawrezce Livermore Laboratory, Rept. UCRL-51456 (1973).

2. COSPAR International Reference Atmosphere 1965 (North-Holland Publishing Co., Amsterdam, 1965).

3. H. Kanter, Phys, Rev. 121, 461 (1961).

4. A. Nelms, Energy Loss and Range of Electrons and Positrons, NBS Circular No. 577 (1956).

5. D. Hamlin, R. Karplus, R. Vik, and K. Watson, J. Geophys, Res. 66, 1 (1961).

6. J. S. Lew, J. Geophyg, Res. 66, 2681 (1961). 